\title{
(Q) Vers la porte de rhodonite (Q)
}

(extraits)

Nous avons faim d'une fin qui ne finirait jamais

Nous avons faim d'infini

Toujours

Jamais

Le temps s'abolit dans les îles Bonaventure de nos vies antérieures des vies avortées que nous ne mettrons jamais au monde alors que nous battons des ailes comme des fous de Bassan sauvages. A peine entendrons-nous, de ces vies lointaines ou naufragées, les cris de détresse des enfants ailés qui déliraient déjà sur les tapis verts des casinos de l'à-venir qui ne viendra

Jamais

Toujours

Nous aurons toujours faim et notre faim ne finira Jamais

Comme cette nuit dans la chambre $8 \mathrm{du}$ Grand Lake Motel dont nous aurons toujours la clé

Ta profondeur plus grande que celle de tous les lacs les mers les océans la nuit nue du ciel ta profondeur comme d'une mer que chaque coup de sonde irait découvrir plus profonde encore plus douloureuse plus douce plus pleine infinie 
L'immensité de toi. Ma parole et les mots que je note comme des cris d'oiseaux qui par milliers viendraient trouer la nuit. Nos corps qui tanguent, nos corps qui roulent, des vagues glissent et montent et nous noient, nous faisons surface pour aspirer une bouffée d'air frais, quelque chose brûle. Au loin passe un vaisseau fantôme dont le vent nous apporte quelques traces de gémissements. Les vagues ont changé de forme, à présent ce sont des dragons qui serpentent entre les jonques vertes et jaunes sur une mer turquoise qui valse au gré de tes boucles d'oreille. Nous essayons de lire les signes, des plongeurs viennent de glisser dans l'eau souple comme de l'huile sauvage, ils cherchent des perles ou peut-être, qui sait, la cité engloutie d'où ils vont remonter, en petits blocs pour orner tes lobes depuis longtemps percés, des pépites de rhodonite rose encore humides.

Le blanc, le noir, l'odeur très douce de toi : des choses très élémentaires, très pures, très harmonieuses dans leur plénitude. L'élégance des bruns, des roses et des bleus, terre claire comme chevelure, soleil couchant sur l'horizon de l'eau, ciel clair comme une promesse. Une bouteille de vin de Grand Pré, Acadie Blanc, une étoile de mer, les récifs basaltiques de Morden où s'échoue le soir comme un grand voilier venu de très loin avec Champlain et Poutrincourt.

Henri-Dominique Paratte

(Acadia University, Wolfville, Nova Scotia)

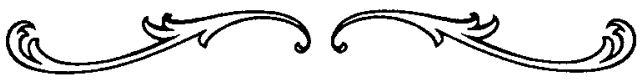

